\title{
Evidence-based practice dynamic capabilities: a concept derivation and analysis
}

\author{
Miao Huo ${ }^{1,2}$, Bolun $\mathrm{Zhao}^{2}, \mathrm{Ye} \mathrm{Li}^{3}$, Jinghua $\mathrm{Li}^{1}$ \\ ${ }^{1}$ School of Public Health, Jilin University, Changchun, China; ${ }^{2}$ School of Nursing, Dalian University, Dalian, China; ${ }^{3}$ Emergency Department, \\ Zhongshan Hospital Affiliated to Dalian University, Dalian, China \\ Contributions: (I) Conception and design: J Li; (II) Administrative support: M Huo; (III) Provision of study materials or patients: Y Li; (IV) Collection \\ and assembly of data: B Zhao; (V) Data analysis and interpretation: M Huo, J Li; (VI) Manuscript writing: All authors; (VII) Final approval of \\ manuscript: All authors. \\ Correspondence to: Jinghua Li. School of Public Health, Jilin University, 1163 Xinmin Street, Changchun 130021, China. Email: jhli@jlu.edu.cn.
}

\begin{abstract}
Background: The environment of healthcare is complex and changeable, and the process of evidencebased practice is "dynamic". Nurses are required to have dynamic capabilities that adjust to changes. However, there is no clear concept of dynamic capabilities in the field of evidence-based practice. The concept of dynamic capabilities needs to be derived from the management field and defined in evidencebased practice.

Methods: A Boolean search of the Web of Science, ProQuest, CINAHL, PubMed, and Emerald databases was conducted, and 35 articles met the inclusion criteria. The concept derivation and analysis strategy of Walker and Avant was used to form and define the concept of evidence-based practice dynamic capabilities. This method includes: selecting a concept, determining the aims of the analysis, identifying usages of the concept, determining the defining attributes, identifying antecedents, consequences, and allied concepts.

Results: Sensing capability, learning capability, integration capability, and coordination capability are attributes of the concept. The antecedents include personal and infrastructure related factors. The consequences include improved patient outcomes, reduced medical costs, and increased nurse job satisfaction. The allied concept is evidence-based practice competence.

Conclusions: An operational definition of the concept was developed. The concept compensates for the shortcomings of the existing "evidence-based practice competence" concept and helps nursing managers establish a new perspective on the effective implementation of evidence-based practice.
\end{abstract}

Keywords: Evidence-based practice; dynamic capabilities; concept derivation; concept analysis

Submitted Nov 12, 2021. Accepted for publication Dec 23, 2021.

doi: 10.21037/atm-21-6506

View this article at: https://dx.doi.org/10.21037/atm-21-6506

\section{Introduction}

Technologies such as artificial intelligence, big data, and cloud computing will push us into a new era of knowledge, where knowledge will become the core of enterprises aiming to gain a competitive advantage. As companies are facing a rapidly changing external environment, they need to be sensitive to environmental changes and quickly adapt, adjust, integrate, and realize knowledge innovation to maintain a long-term competitive advantage. This is "dynamic capability", namely, "the firm's ability to integrate, build, and reconfigure internal and external competences to address rapidly changing environments" (1).

The essence of evidence-based practice is knowledge innovation. Evidence-based practice is a problem-solving approach to clinical care that incorporates the conscious use of the best available scientific evidence, clinicians' expertise, and patients' values (2). As nurses face changes in the context of healthcare services, such as the emergence 
of a large body of constantly updated evidence, changes in medical knowledge and technology, diverse patient care needs and preferences, different stakeholder attitudes, and changing medical institution resources and conditions, they need to weigh multiple relationships and interests, integrate evidence with internal and external competences, and optimally implement evidence-based practice (3-5), which requires "dynamic capabilities". However, there is no concept of dynamic capabilities in the field of evidencebased practice. Thus, clarifying the concept of dynamic capabilities in the context of evidence-based practice is of great significance to promote evidence-based practice from a new perspective.

In complex external environments, dynamic capabilities enable an enterprise to respond to environmental changes, and they comprise a process by which an organization constantly seeks new knowledge and applies it to change its own capabilities. Winter proposed a hierarchical model (6). The first type of capability is ordinary capabilities (zero level), which ensures only the survival of an enterprise in the market. The second category is dynamic capabilities, which are more extensive than ordinary capabilities, including the ability to adapt to changes (first level) and the ability to create new capabilities (second level). Dynamic capabilities provide the ability to apply ordinary capabilities (7).

In the context of evidence-based practice, the best balance among complex, diverse, and dynamic elements (patients, stakeholders, clinical situations, etc.) needs to be achieved and the best evidence must be applied to nursing practice. However, finding a dynamic balance is extremely challenging for nurses. The Advancing Research and Clinical Practice Through Close Collaboration (ARCC) model (8) emphasizes that evidence-based practice requires not only evidence-based practice knowledge and skills, but also keen insight. This enables the prompt discovery of evidence-based practice obstacles in an organizational environment and the active adoption of strategies needed to solve problems, thus promoting evidence-based practice. In this model, evidence-based practice knowledge and skills are ordinary capabilities, and the capabilities to promote evidence-based practice are dynamic capabilities. Together, ordinary capabilities and dynamic capabilities constitute evidence-based practice competence.

At present, many studies focus on evidence-based practice competence. This has been defined as "the ability to ask clinically relevant questions for the purposes of acquiring, appraising, applying, and assessing multiple sources of knowledge within the context of caring for a particular patient, group, or community" (9). Schaefer and Welton argued that this concept should be defined as "the nurse's perceived knowledge and beliefs about evidencebased practice, a nurse's familiarity with, attitudes toward and perceived self-efficacy and the level of skill toward searching for and appraising evidence" (10). Evidencebased practice competence is a concept that incorporates evidence-based practice knowledge, skills, and attitudes (11). Nurses can prove their evidence-based practice competence in 4 ways, through: (I) knowledge (for example, by formulating a structured answerable question); (II) ability (for example, by searching medical databases); (III) performance (for example, through critical evaluation); (IV) behavior (for example, by applying the results of practice). Scholars have attached great importance to the first 3 steps, however, for implementing evidence-based practice, the whole process must be considered (12). Of those that exist, many instruments of evidence-based practice competence have excluded coverage of the behavior domain of evidencebased practice (13). Similarly, evidence-based practice education or training only paid attention to the teaching of knowledge, skills, but ignored other capabilities in the evidence-based practice behavior. A person who possesses knowledge and skills is not necessarily able to use them flexibly in a changeable environment (14). This is why many nurses receive evidence-based practice training, but the implementation rate is still very low. Evidence-based practice processes require more advanced capabilities (9), such as sensing capability, integration capability, learning capability, coordination capability. We find that the definition of evidence-based practice competence mostly focuses on evidence-based practice, namely "knowledge, skills, and attitudes", which are ordinary capabilities, while neglecting nurses' perceptions of their environment, resource reconfiguration, organizational learning, and coordination in the implementation process, which are dynamic capabilities. The current definition of evidencebased practice competence does not cover this. It is very necessary to introduce the concept of dynamic capabilities in evidence-based practice to compensate for the shortcomings of the existing "evidence-based practice competence" concept.

Through a literature review, it can be confirmed that there is no relevant research on dynamic capabilities in the field of evidence-based practice. Therefore, this research adopts the concept construction strategy of Walker and Avant (15) to derive the idea of "dynamic capabilities" in the field of evidence-based practice, form a concept of evidence- 
based practice dynamic capabilities, and clarify its attributes, antecedents, consequences, and allied concepts, which were obtained from the literature about the antecedents, consequences and allied concepts of evidence based practice or evidence based practice competence.

\section{Methods}

The basis of concept derivation lies in an analogy between phenomena in two fields. By looking to a defined source or parent field for an analog to aid in developing a new field of interest, concepts in the new field may be derived. Further, by redefining concepts from the parent field to fit the new field, a new set of concepts is created. Redefinition is more than just assigning a slightly modified definition to a word. The redefinition that occur in the concept derivation requires that derived concepts be associated with new field by definitions, resulting in a truly innovative way of looking at phenomena in new field (15). The core of the derivation strategy involves transposing and redefining or explaining the concept of a known field through "analogy" or "metaphor" so that it can be applied to develop a theoretical idea that does not yet exist, to update the original theory, or to develop a new perspective. There are 4 steps within this process: (I) be familiar with the existing literature related to the topic of interest; (II) examine other fields for new perspectives on the topic of interest; (III) choose a parent concept or a set of concepts from another field to use in the derivation process; (IV) redefine the concept or set of concepts from the parent field in terms of the topic of interest. According to the literature, we analyzed the antecedents, attributes, consequences, and allied concepts of the new concept.

\section{Literature search}

Boolean search is the most basic method of database search. It uses logical "or" (+, OR), logical "and" ( $\times$, AND), logical "not" (-, NOT) and other operators to search for related documents in the database. A Boolean search was conducted using the following terms: evidence-based nursing, evidence-based practice, dynamic capability, dynamic capabilities, concept, definition, and model. The databases searched included the Web of Science, ProQuest, Cumulative Index to Nursing and Allied Health Literature (CINAHL), PubMed, and Emerald databases. The search results were limited to those published after 1 January 1995.

In the case of Web of Science, the search strategy was (evidence-based nursing [Title] OR evidence-based practice [Title]) AND (concept [Title] OR definition [Title] OR model [Title]), (dynamic capability [Title] OR dynamic capabilities [Title]) AND (concept [Title] OR definition [Title] OR model [Title]).

\section{Inclusion and exclusion criteria}

The literature inclusion criteria were as follows: (I) expression and explanation of the concept of evidencebased practice and/or dynamic capabilities; (II) qualitative research, quantitative research, mixed-methods research, or a literature review. The exclusion criteria were as follows: (I) literature with a direct use of existing concepts; (II) literature that was inaccessible; or (III) literature that was not in English.

\section{Literature screening}

After applying the inclusion and exclusion criteria, 2 researchers conducted an independent preliminary screening of the remaining literature by reading the titles and abstracts of the included studies. Then, they read the full texts during a second screening. If there was a disagreement, it was resolved through negotiation with a third researcher (Figure 1).

\section{Literature integration}

The concept of "dynamic capabilities" was derived in the field of "evidence-based practice", and the antecedents, attributes, consequences, and allied concepts of the new concept were analyzed.

\section{Statistical analysis}

Burns and Grove's four-phased approach to review literature was adopted. This included: skimming, comprehension, analysis, and synthesis. Skimming related to reviewing the articles titles, abstracts and themes to include or exclude articles for review. After the article was reviewed, it was considered significant in content and provided background to factors pertinent to the concept of evidence based practice/dynamic capabilities. Comprehension was related to critically reviewing the key concepts, topics about the content of the article. Analyzing invoked the skills of critical appraisal which include reviewing, comparing and contrasting to formulate key concepts and themes. 




Figure 1 Literature search and selection process.

Synthesizing involved clarifying the meaning of all the information gathered as part of the literature review.

\section{Results}

\section{Definitions of dynamic capabilities}

Dynamic capabilities refer to the capabilities of a firm to be sensitive and reallocate their resources to match changes in their environments. The majority of studies on dynamic capabilities treat the definition developed by Teece (1997) as the original definition of dynamic capabilities (16), and this study defines the concept as "the firm's ability to integrate, build, and reconfigure internal and external competences to address rapidly changing environments" (1). Dynamic capabilities can extend, modify, or create ordinary capabilities (6). Zollo and Winter believed that dynamic capabilities are high-level capabilities built on ordinary or low-level capabilities (17). Eisenhardt and Martin argued that dynamic capabilities can be understood as routines of "best practice" and proposed that dynamic capabilities are "the firm's processes that use resources specifically the processes to integrate, reconfigure, gain and release resources to match and even create market change" (18). Dynamic capabilities are the result of the continuous accumulation of tacit knowledge and explicit knowledge (19). Denford believed that the formation of dynamic capabilities is based on knowledge innovation and application (20). Tallott and Hilliard pointed out that firms first use their internal absorptive capabilities to obtain knowledge outside the organization and then rely on their knowledge integration capabilities to achieve internal knowledge innovation within the organization, which in turn promotes the formation of dynamic capabilities (21). Although different scholars provide different definitions and explanations of dynamic capabilities, these different viewpoints all adhere to the same idea, namely that dynamic capabilities are behaviors or capabilities related to the allocation of resources and the learning and absorbing of new knowledge. 
The dimensions of dynamic capabilities mainly include the following: (I) sensing capability (22-26), namely, the capability to discover, explain, and pursue opportunities in an environment (this includes scanning, searching for and understanding customer needs, technical possibilities, markets, and supplier and competitor responses); (II) learning capability (23-28), which is defined as the capability to use new knowledge to improve existing ordinary capabilities; (III) integration capability $(1,23-26,28,29)$, which refers to the capability to reconfigure resources to adapt to changes in an environment; and (IV) coordination capability $(23,26,27)$, which is defined as the capability to coordinate deployment tasks and resources. This research employs the dynamic capabilities concept of Teece (1) and the dimension of Pavlou and Sawy (23) as a parent concept.

\section{Definitions of evidence-based practice}

Concerning definitions of evidence-based practice, the themes emerging from the examined literature identified evidence-based practice as a process (30-32). During the early development of evidence-based practice, scholars focused on the process of "evidence generation". Evidencebased practice was defined as a "method of problem solving which involves identifying the clinical problem, searching the literature, evaluating the research evidence and deciding on the intervention" (33). Evidence-based practice emphasizes examining research and "evaluating its strengths and weaknesses, synthesizing sometimes divergent conclusions, and applying the resulting insights to daily patient care" (34). As understanding of evidencebased practice has increased, the definition of evidencebased practice has trended towards "applying evidence", with an emphasis on integrating the best evidence and multiple elements in the context of clinical care. Evidence-based practice means "integrating the best available research evidence with information about patient preferences, clinician skill level, and available resources to make decisions about patient care" (35). Jordan et al. conceptualized evidence-based practice in the Joanna Briggs Institute model as "clinical decision-making that considers the best available evidence; the context in which the care is delivered, client preference and the professional judgment of the health professional" (36). After reviewing 83 documents involving evidence-based practice or evidencebased nursing concepts, 11 core elements were extracted, namely, the identification of research, the evaluation of research, applications of research, the use of best evidence, the evaluation of care, problem solving, decision making, clinical/professional expertise, a theory-driven approach, patient involvement, and a process-based method (31). With the development of evidence-based practice, additional system factors have been added to this process, such as the evidence-based practice culture of healthcare organizations, leaders' support, resources, and the availability of evidencebased practice mentors (37). Karlsson et al. (32) added organizational elements to the definition of evidence-based practice, which is "both an approach and a process based on scientific knowledge, patient needs and experiences, clinical experience, and supportive organizational and economic conditions". The successful implementation of evidencebased practice is a dynamic process dependent on a number of variables (individual experiences, bias, and attitudes alongside professional, organizational, and workplace factors) (38). Nadalin Penno et al. analyzed existing evidence-based practice frameworks/models/theories and summarized 7 factors that affect the sustainability of evidence-based practice, including innovation, adopters, leadership and management, inner contexts, inner processes, outer contexts, and outcomes (5). The process of evidencebased practice is becoming increasingly complex. Nurses are faced with a large number of obstacles related to evidencebased practice, and they need to integrate evidence with internal and external knowledge and organizational factors. Translating the best evidence into evidence-based practice poses a significant challenge.

\section{Discussion}

\section{Attributes of evidence-based practice dynamic capabilities}

\section{Sensing capability}

In the context of evidence-based practice, sensing capabilities mainly emphasize the perceptions of organizations or individuals regarding factors such as scientific research results, patient preferences, clinical collaborators, clinical competitors, medical institution requirements, management, technological changes, policies, or clinical competition and development. The capability to recognize and respond to external information is central to the entire evidence-based practice process. Thus, whether an evidence-based organization or individual can capture relevant information in a timely manner mainly depends on whether the entity can effectively and continuously gain insights (5). Therefore, a keen perception of the environment is a prerequisite for the realization of evidence-based practice, but nurses find this to be difficult. 
A report pointed out that nurses face barriers to perception due to a lack of self-confidence and knowledge: "I just feel like I'm (at) such an elementary level where like I'm still having people tell me to go look up things as opposed to me doing it on my own." (39).

\section{Integration capability}

In the context of evidence-based practice, integration capability is mainly reflected by the integration of evidence, real resources, and organizational culture (11), and it is mainly divided into 2 steps: evaluation and reconfiguring. During this process, evidence is processed and absorbed by localized organizations, and this forms innovative evidence.

First, evidence is searched, evaluated, screened, and integrated into the form of "best evidence", but this "best evidence" cannot be directly applied to actual clinical practice. Nurses must fully analyze their actual clinical situations, assessing other nurses (their attitudes, knowledge and technical levels, experience, concerns, etc.), the degree of recognition and support received from stakeholders, patients' levels of acceptance, willingness, and financial commitment, and their current actual nursing status to reveal the gap between their reality and evidence-based practice. In addition, it is necessary to evaluate the human resources, hospital equipment, medical materials, funding, administrative support, and level of teamwork available. Second, on the basis of these assessments, nurses must reevaluate the applicable evidence and reallocate their existing resources by reviewing the clinical applicability of the evidence, forming workflow, standards, and evaluation methods, designing pre-experiment plans and reforming implementation plans, building a multidisciplinary evidencebased practice team, and redistributing resources such as manpower, medical equipment, and medical consumables.

\section{Learning capability}

Healthcare units not only strive to stabilize existing medical practices, but also strive to learn, adapt, and implement new practice routines, as there remains a major gap between existing and desired performance (4). The literature recommends a lifelong learning approach to evidence-based practice (12). Behavioral change interventions that have been shown to promote evidence-based practice include: printed educational materials; educational meetings; educational outreach; local opinion leaders; audit and feedback; and reminders (40). In the context of evidencebased practice, learning is the most important tool, which allows organizations to take a leap from existing practices to implement new practices (41). Moreover, organizational learning is a complement to and a continuation of exploration and innovation capabilities. It can not only reveal and draw on the excellent quality and advanced experience of others, but more importantly, it is of great significance to the sustainable growth of evidence-based practice.

\section{Coordination capability}

Many people and situations are involved in evidence-based practice $(5,11)$. It is necessary to dynamically coordinate various relationships in an environment. Factors such as confidence in relation to change, interdisciplinary support, clear guidance from mentors, leadership support, and dynamic feedback $(42,43)$ are considered evidence-based practice facilitators. How can these facilitating factors be acquired? Coordination capability is important among nurses, and they need to coordinate using their own leadership, interpersonal communication, and teamwork skills to effectively control evidence-based practice implementation processes and maintain the internal stability of their organizations (44).

\section{Antecedents of evidence-based practice dynamic capabilities}

Antecedents are events that must occur prior to the occurrence of a phenomenon (15). The antecedents of evidence-based practice dynamic capabilities are divided into personal and infrastructure related factors. Since dynamic capabilities enable ordinary capabilities, individual evidence-based practice competence (individual innovation, attitude, knowledge, and skill) is one of the antecedents of evidence-based practice dynamic competence (45). Another antecedent of personal factors is motivation, namely, the willingness and ability to actively acquire external knowledge or evidence. Work overload and resistance to changes in practice (46) often result in a lack of willingness to acquire external knowledge, which is a common barrier to evidence-based practice implementation. Infrastructure has been defined as the structures and processes that are set up to enable the smooth and effective execution of evidence-based practice (47). It can be summarized as available resources, such as evidence $(48,49)$, equipment, medical materials, funding, social capital, and social networks $(46,50)$.

\section{Consequence of evidence-based practice dynamic capabilities}

The consequence of evidence-based practice dynamic 
capabilities is the ability to carry out evidence-based practice more effectively. From the perspective of patients, its direct result is that evidence-based practice can improve service quality, improve patient outcomes, reduce costs, and improve patient satisfaction $(2,13,51)$. From the perspective of nurses, it can improve team cooperation, provide a harmonious working atmosphere, and improve job satisfaction. From the perspective of team organization, the resulting improvement of service quality can reduce bed turnover and improve service performance (52).

\section{Allied concepts}

An allied concept is evidence-based practice competence, though there are differences between the 2 ideas. First, from a hierarchical perspective, evidence-based practice competence emphasizes the existence of a relatively stable stock of knowledge, skills, and attitudes over a certain period of time (9). It involves a relatively static ability to maintain evidence-based practice, and it entails zero-level capabilities. Evidence-based practice dynamic capabilities emphasize nurses' recognition of dynamic environments, seizing opportunities to carry out knowledge innovation, and reconfiguring the internal and external resources of organizations to respond to their rapidly changing environments. It is a reflection of changes in the external environment. Evidence-based practice dynamic capabilities employ evidence-based practice competence to integrate internal and external resources, and they serve as a mechanism underlying effective evidence-based practice. Second, from the perspective of behavioral characteristics, evidence-based practice competence gives attention to scientific, rigorous, and prudential evidence-based steps and has the rigid characteristics of mechanization and stylization. Evidence-based practice dynamic capabilities emphasize dealing with constantly changing and shifting environments as well as innovating and reconfiguring, and they are flexible and adaptable.

\section{Proposed definition of evidence-based practice dynamic capabilities}

In this study, the essence of evidence-based practice dynamic capabilities was explored by examining its associated definitions, attributes, antecedents, consequence and allied concepts. The concept of evidence-based practice competence has been discussed much in the literatures. However, the concept of evidence-based practice competence has limitations, which the concept of evidencebased practice dynamic capabilities can compensate for.

Evidence-based practice is a process of transformation. This change is triggered by changes introduced due to new evidence and new needs. Based on this analysis, it is proposed that evidence-based practice dynamic capabilities can be defined as "the ability to dynamically identify and perceive changes in the external environments, explore and learn new knowledge and the best evidence, seize opportunities to conduct knowledge/evidence innovation considering different elements (stakeholders, patients, clinical situations, their own professional knowledge and skills, etc.), change existing practices, processes, and management approaches, reallocate internal and external organizational resources to respond to rapidly changing environment, and provide quality nursing services."

\section{Implications for nursing management}

Having a clear and operational definition of evidence-based practice dynamic capabilities provides a foundation for the development of instruments measuring for evidence-based practice dynamic capabilities, which could compensate for the shortcomings of the existing "evidence-based practice competence" measurement. The analysis of antecedents and attributes will help nurse managers and educators to establish a new perspective on the effective implementation of evidence-based practice, and further consider strategies to promote evidence-based practice competence, motivation, infrastructure and collaboration, in order to maximize patients' outcomes and improve the quality of care.

\section{Limitations}

Since dynamic capabilities belong to the field of strategic management, related research in the health field is in its infancy. Only the Emerald database which focuses the management field was selected, while the other databases focus on medical and health care, limiting our search for research on "dynamic capabilities". In addition, only English articles were selected, which limited the comprehensiveness of our literature retrieval.

\section{Conclusions}

In summary, in the context of evidence-based practice, nurses must be able to dynamically identify and perceive changes in their external environments, seize opportunities for knowledge innovation, select and use the most effective 
technologies, comprehensively consider patients and their actual clinical situations, and reconfigure the internal and external resources of organizations to cope with their rapidly changing environments. Therefore, the introduction of evidence-based practice dynamic capabilities can compensate for the shortcomings of the current concept of "evidence-based practice competence" and provide a reference for measuring evidence-based practice dynamic capabilities, education, and training. However, since this research introduces the concept of dynamic capabilities to the context of evidence-based practice for the first time, it is inevitable that there are deficiencies that need to be further explored and studied.

\section{Acknowledgments}

The authors acknowledge Changhong Liu for her assistance with formatting and manuscript submission.

Funding: None.

\section{Footnote}

Conflicts of Interest: All authors have completed the ICMJE uniform disclosure form (available at https://dx.doi. org/10.21037/atm-21-6506). The authors have no conflicts of interest to declare.

Etbical Statement: The authors are accountable for all aspects of the work in ensuring that questions related to the accuracy or integrity of any part of the work are appropriately investigated and resolved.

Open Access Statement: This is an Open Access article distributed in accordance with the Creative Commons Attribution-NonCommercial-NoDerivs 4.0 International License (CC BY-NC-ND 4.0), which permits the noncommercial replication and distribution of the article with the strict proviso that no changes or edits are made and the original work is properly cited (including links to both the formal publication through the relevant DOI and the license). See: https://creativecommons.org/licenses/by-nc-nd/4.0/.

\section{References}

1. Teece DJ, Pisano G, Shuen A. Dynamic capabilities and strategic management. Strateg Manag J 1997;18:509-33.

2. Melnyk BM, Tan A, Hsieh AP, et al. EvidenceBased Practice Culture and Mentorship Predict EBP
Implementation, Nurse Job Satisfaction, and Intent to Stay: Support for the ARCC@ Model. Worldviews Evid Based Nurs 2021;18:272-81.

3. Nembhard IM, Tucker AL. Deliberate learning to improve performance in dynamic service settings evidence from hospital intensive care units. Organ Sci 2011;22:907-22.

4. Mittal S. How organizations implement new practices in dynamic context: role of deliberate learning and dynamic capabilities development in health care units. J Knowl Manag 2019;23:1176-95.

5. Nadalin Penno L, Davies B, Graham ID, et al. Identifying relevant concepts and factors for the sustainability of evidence-based practices within acute care contexts: a systematic review and theory analysis of selected sustainability frameworks. Implement Sci 2019;14:108.

6. Winter SG. Understanding Dynamic Capabilities. Strateg Manag J 2003;24:991-5.

7. Chien SY, Tsai CH. Dynamic capability, knowledge, learning, and firm performance. J Organ Change Manage 2012;25:434-44.

8. Melnyk BM, Fineout-Overholt E, Gallagher-Ford L, et al. Evidence-based practice, step by step: sustaining evidencebased practice through organizational policies and an innovative model. Am J Nurs 2011;111:57-60.

9. Laibhen-Parkes N. Evidence-based practice competence: a concept analysis. Int J Nurs Knowl 2014;25:173-82.

10. Schaefer JD, Welton JM. Evidence based practice readiness: A concept analysis. J Nurs Manag 2018;26:621-9.

11. Labrague LJ, McEnroe-Petitte D, D'Souza MS, et al. A Multicountry Study on Nursing Students' Self-Perceived Competence and Barriers to Evidence-Based Practice. Worldviews Evid Based Nurs 2019;16:236-46.

12. Ramis MA, Chang A, Nissen L. Undergraduate Health Students' Intention to Use Evidence-Based Practice After Graduation: A Systematic Review of Predictive Modeling Studies. Worldviews Evid Based Nurs 2018;15:140-8.

13. Hu MY, Wu YN, McEvoy MP, et al. Development and validation of the Chinese version of the evidence-based practice profile questionnaire (EBP2Q). BMC Med Educ 2020;20:280.

14. Bonetti D, Johnston M, Pitts NB, et al. Can psychological models bridge the gap between clinical guidelines and clinicians' behaviour? A randomised controlled trial of an intervention to influence dentists' intention to implement evidence-based practice. Br Dent J 2003;195:403-7; discussion 387.

15. Walker LO, Avant KC. Strategies for theory construction in nursing. Fifth edition ed. Boston: Prentice Hall/ 
Pearson, 2014.

16. Strønen F, Hoholm T, Kværner K, et al. Dynamic capabilities and innovation capabilities: The case of the 'Innovation Clinic'. J Entrep Innov Manag 2017;13:89-116.

17. Zollo M, Winter SG. Deliberate Learning and the Evolution of Dynamic Capabilities. Organ Sci 2002;13:339-51.

18. Eisenhardt KM, Martin JA. Dynamic Capabilities: What Are They. Strateg Manag J 2000;21:1105-21.

19. Ellonen HK, Wikstrom P, Jantunen A. Linking dynamic-capability portfolios and innovation outcomes. Technovation 2009;29:753-62.

20. Denford JS. Building knowledge: developing a knowledgebased dynamic capabilities typology. J Knowl Manag 2013;17:175-94.

21. Tallott M, Hilliard R. Developing dynamic capabilities for learning and internationalization. Balt J Manag 2016;11:328-47.

22. Teece DJ. Explicating dynamic capabilities: the nature and microfoundations of (sustainable) enterprise performance. Strateg Manag J 2007;28:1319-50.

23. Pavlou PA, Sawy OAE. Understanding the Elusive Black Box of Dynamic Capabilities. Decision Sci 2011;42:239-73.

24. Singh R, Charan P, Chattopadhyay M. Dynamic capabilities and responsiveness Moderating effect of organization structures and environmental dynamism. Decision 2019;46:301-19.

25. Mudalige D, Ismail NA, Malek MA. Exploring the role of individual level and firm level dynamic capabilities in SMEs' internationalization. J Int Entrep 2019;17:41-74.

26. Ilmudeen A, Bao Y, Alharbi IM, et al. Revisiting dynamic capability for organizations' innovation types. Eur J Innov Manag 2021;24:507-32.

27. Caloghirou Y, Kastelli I, Tsakanikas A. Internal capabilities and external knowledge sources: complements or substitutes for innovative performance? Technovation 2004;24:29-39.

28. Wu LY. Entrepreneurial resources, dynamic capabilities and start-up performance of Taiwan's high-tech firms. J Bus Res 2007;60:549-55.

29. Constance E. Helfata RSR. Dynamic and integrative capabilities for profiting from innovation in digital platform-based ecosystems. Research Policy, 2018. Available online: https://ssrn.com/abstract=3122046

30. Flemming K. Asking answerable questions. Evid Based Nurs 1998;1:36-7.

31. Scott K, McSherry R. Evidence-based nursing: clarifying the concepts for nurses in practice. J Clin Nurs
2009;18:1085-95.

32. Karlsson A, Lindeborg P, Gunningberg L, et al. Evidencebased nursing-How is it understood by bedside nurses? A phenomenographic study in surgical settings. J Nurs Manag 2019;27:1216-23.

33. White SJ. Evidence-based practice and nursing: the new panacea? Br J Nurs 1997;6:175-8.

34. DeGeorges KM. Evidence! Show me the evidence! Untangling the web of evidence-based health care. AWHONN Lifelines 1999;3:47-8.

35. Ciliska DK, Pinelli J, DiCenso A, et al. Resources to enhance evidence-based nursing practice. AACN Clin Issues 2001;12:520-8.

36. Jordan Z, Lockwood C, Munn Z, et al. The updated Joanna Briggs Institute Model of Evidence-Based Healthcare. Int J Evid Based Healthc 2019;17:58-71.

37. Melnyk BM. Breaking Down Silos and Making Use of the Evidence-Based Practice Competencies in Healthcare and Academic Programs: An Urgent Call to Action. Worldviews Evid Based Nurs 2018;15:3-4.

38. Williams B, Perillo S, Brown T. What are the factors of organisational culture in health care settings that act as barriers to the implementation of evidence-based practice? A scoping review. Nurse Educ Today 2015;35:e34-41.

39. Lam CK, Schubert CF, Herron EK. Evidence-Based Practice Competence in Nursing Students Preparing to Transition to Practice. Worldviews Evid Based Nurs 2020;17:418-26.

40. Drury P, McInnes E, Hardy J, et al. Stroke unit Nurse Managers' views of individual and organizational factors liable to influence evidence-based practice: A survey. Int J Nurs Pract 2016;22:169-78.

41. Damschroder LJ, Aron DC, Keith RE, et al. Fostering implementation of health services research findings into practice: a consolidated framework for advancing implementation science. Implement Sci 2009;4:50.

42. Lam CK, Schubert C. Evidence-Based Practice Competence in Nursing Students: An Exploratory Study With Important Implications for Educators. Worldviews Evid Based Nurs 2019;16:161-8.

43. De Leo A, Bayes S, Bloxsome D, et al. Exploring the usability of the COM-B model and Theoretical Domains Framework (TDF) to define the helpers of and hindrances to evidence-based practice in midwifery. Implement Sci Commun 2021;2:7.

44. Tucker S, Klotzbach L, Olsen G, et al. Lessons learned in translating research evidence on early intervention programs into clinical care. MCN Am J Matern Child 
Nurs 2006;31:325-31.

45. Mohammadi MM, Poursaberi R, Salahshoor MR. Evaluating the adoption of evidence-based practice using Rogers's diffusion of innovation theory: a model testing study. Health Promot Perspect 2018;8:25-32.

46. Camargo FC, Iwamoto HH, Galvão CM, et al. Competences and Barriers for the Evidence-Based Practice in Nursing: an integrative review. Rev Bras Enferm 2018;71:2030-8.

47. Chen Q, Sun M, Tang S, et al. Research capacity in nursing: a concept analysis based on a scoping review. BMJ Open 2019;9:e032356.

48. Pravikoff DS, Tanner AB, Pierce ST. Readiness of U.S. nurses for evidence-based practice. Am J Nurs 2005;105:40-51; quiz 52.

49. Thorsteinsson HS, Sveinsdóttir H. Readiness for and

Cite this article as: Huo M, Zhao B, Li Y, Li J. Evidence-based practice dynamic capabilities: a concept derivation and analysis. Ann Transl Med 2022;10(1):22. doi: 10.21037/atm-21-6506 predictors of evidence-based practice of acute-care nurses: a cross-sectional postal survey. Scand J Caring Sci 2014;28:572-81.

50. Dalheim A, Harthug S, Nilsen RM, et al. Factors influencing the development of evidence-based practice among nurses: a self-report survey. BMC Health Serv Res 2012;12:367.

51. Bonham CA, Sommerfeld D, Willging C, et al. Organizational factors influencing implementation of evidence-based practices for integrated treatment in behavioral health agencies. Psychiatry J 2014;2014:802983.

52. Titler MG, Cullen L, Ardery G. Evidence-based practice: an administrative perspective. Reflect Nurs Leadersh 2002;28:26-7, 46, 45.

(English Language Editor: C. Betlazar-Maseh) 